\title{
Expression of Myeloid Differentiation Antigens on Normal and Malignant Myeloid Cells
}

\author{
James D. Griffin, Jerome Ritz, Lee M. Nadler, and Stuart F. Schlossman, \\ Division of Tumor Immunology, Sidney Farber Cancer Institute, and \\ Harvard Medical School, Boston, Massachusetts 02115
}

\begin{abstract}
A B S T RA C T A series of monoclonal antibodies have been characterized that define four surface antigens (MY3, MY4, MY7, and MY8) of human myeloid cells. They were derived from a fusion of the NS-1 plasmacytoma cell line with splenocytes from a mouse immunized with human acute myelomonocytic leukemia cells. MY3 and MY4 are expressed by normal monocytes and by $>90 \%$ of patients with acute monocytic leukemia or acute myelomonocytic leukemia, but are detected much less often on other types of myeloid leukemia. MY7 is expressed by granulocytes, monocytes, and $5 \%$ of normal bone marrow cells. $79 \%$ of all acute myeloblastic leukemia (AML) patients tested (72 patients) express MY7 without preferential expression by any AML subtype. MY8 is expressed by normal monocytes, granulocytes, all peroxidase-positive bone marrow cells, and 50\% of AML patients. MY3, MY4, and MY8 define myeloid differentiation antigens in that they are not detected on myeloid precursor cells and appear at discrete stages of differentiation. These antigens are not expressed by lymphocytes, erythrocytes, platelets, or lymphoid malignancies. The monoclonal antisera defining these antigens have been used to study differentiation of normal myeloid cells and malignant myeloid cell lines.
\end{abstract}

\section{INTRODUCTION}

Mature myeloid cells are derived from a population of pluripotent hematopoietic stem cells that have the capacity for both self-renewal and differentiation (1-3). The progeny of these stem cells include several committed precursor cells that give rise separately to erythroid cells, megakaryocytes, and to granulocytes and monocytes. Differentiation of the gran-

Received for publication 9 April 1981 and in revised form 15 June 1981. ulocyte-monocyte precursor cell into later myeloid cells depends, at least in vitro, on the presence of colony-stimulating activity, a group of substances produced by monocytes, activated $\mathrm{T}$ cells, and certain other cells $(4,5)$. Although later stages of myeloid differentiation are readily identifiable by changes in morphology and histochemistry, the detailed study of early myeloid differentiation has been difficult because of the small numbers of these precursor cells and their lack of distinctive morphological or biochemical features.

The immunological identification of surface antigens of myeloid cells may be a valuable technique for studying myeloid differentiation. Such studies with lymphocyte antigens have proven valuable in the identification of lymphocyte types and subsets (6), and it has been possible to relate certain lymphocytic malignancies to a normal cell counterpart, such as a $B$ cell or $T$ cell by virtue of shared antigenic markers $(7-10)$. This has led to the discovery of clinically important, and previously unrecognized, subgroups of patients with lymphocytic leukemia and lymphoma (8). Experiments with several heteroantisera prepared against myeloid cells have shown that maturation-linked antigens can be detected, and some of these myeloid antigens are also expressed on acute myeloblastic leukemia cells (11-15). In addition, the existence of leukemia-specific antigens has been postulated, but not conclusively demonstrated (13). Although heteroantisera have proven useful, the extensive absorptions that are required often yield antisera with low titers, thus limiting utility for biological or clinical investigations. The development of technology to produce monoclonal antibodies has eliminated the problems of heteroantisera with respect to specificity and reproducibility, and has led to rapid advances in the field of lymphocyte surface markers (16).

In an effort to study the surface antigens of normal and leukemic myeloid cells, we have gen- 
erated a series of myeloid-specific monoclonal antibodies (MY3, MY4, MY7, MY8) after immunization with the blast cells from a patient with acute myelomonocytic leukemia. The reactivity of these antisera with normal and malignant cells, and evidence that such antisera may define myeloid differentiation antigens are presented.

\section{METHODS}

Production of monoclonal antibodies. A 6-wk-old female BALB/c mouse (The Jackson Laboratory, Bar Harbor, Maine) was immunized with cryopreserved leukemic cells from a single patient with acute myelomonocytic leukemia. The immunization schedule consisted of an initial subcutaneous injection of $10^{7}$ leukemic cells emulsified in complete Freund's adjuvant (Difco Laboratories, Detroit, Mich.), followed by three weekly injections of $10^{7}$ viable cells in phosphate-buffered saline. 6 mo later, $10^{7}$ leukemic cells from the same donor were injected intravenously on two consecutive days. Splenectomy was performed $3 \mathrm{~d}$ later, and somatic cell hybridization carried out by the method of Kohler and Milstein (17), with modifications (18). $2.4 \times 10^{8}$ mouse splenocytes were fused with $3.0 \times 10^{7} \mathrm{P} 3 / \mathrm{NS} 1 / 1-\mathrm{Ag} 4-1$ myeloma cells (provided by Dr. R. Kennett, University of Pennsylvania, Philadelphia, Pa.) in the presence of $0.5 \mathrm{ml}$ polyethylene glycol, $30 \%$ in Dulbecco's minimal essential medium (Microbiological Associates, Walkersville, Md.), for $8 \mathrm{~min}$ at $23^{\circ} \mathrm{C}$. After washing, the fused cell mixture was suspended in hypoxanthine-aminopterin-thymidine medium (19) supplemented with $10 \%$ fetal calf serum $(\mathrm{FCS})^{1}$ and $10 \%$ horse serum, and distributed to 600 microtiter wells. The hybridoma cells were grown at $37^{\circ} \mathrm{C}$ in a humidified atmosphere containing $7 \% \mathrm{CO}_{2}$ in air. $14-21 \mathrm{~d}$ later, 100 microliters of supernate from wells exhibiting active growth of clones was tested for the presence of antibody reactive with the leukemic blasts from the original patient by an indirect immunofluorescence assay. $1 \times 10^{6}$ blast cells were incubated at $4^{\circ} \mathrm{C}$ with culture supernate for $30 \mathrm{~min}$, washed two times with medium containing $2.5 \%$ human $\mathrm{AB}$ serum, and stained with fluorescein-conjugated $F\left(a b^{\prime}\right)_{2}$ fragments of goat anti-mouse Ig (prepared by Mr. Herbert Levine, Sidney Farber Cancer Institute) for $30 \mathrm{~min}$ at $40^{\circ} \mathrm{C}$. After two additional wash steps, fluorescent antibody-coated cells were detected on a fluorescence-activated cell sorter (FACS-1, Becton-Dickinson \& Co., Mountain View, Calif.); or a cytofluorograph (FC200/4800A, Ortho Instruments, Westwood, Mass.). Background fluorescence was measured by testing the supernate from a well of a nonproducing clone or from a previously generated clone producing an antibody known not to be reactive with the test cells. Anti-human $\beta 2$ antigen and anti-Ia monoclonal antibodies were used as positive

${ }^{1}$ Abbreviations used in this paper: ALL, acute lymphocytic leukemia; AML, acute myeloblastic leukemia; AMML, acute myelomonocytic leukemia; AMoL, acute monocytic leukemia; APL, acute promyelocytic leukemia; CALLA, common acute lymphocytic leukemia antigen; CFU-GM, granulocyte/macrophage colony forming unit; $\mathrm{CML}$, chronic myelogenous leukemia; DMSO, dimethylsulfoxide; FACS, fluorescence-activated cell sorter; FCS, fetal calf serum; NSE, nonspecific esterase; PHA-LCM, phytohemagglutininstimulated leukocyte-conditioned medium; TPA, 12-O-tetradecanoylphorbol-13-acetate. controls. Wells containing antibody reactive with the immunizing blast cells were next screened for reactivity with an autologous B lymphoblastoid cell line, Laz 334 (kindly provided by Dr. Herbert Lazarus, Sidney Farber Cancer Institute, Boston, Mass.). Primary cultures that were nonreactive with the autologous $B$ cell line were recloned by limiting dilution (20), and subsequently maintained by injection of $1 \times 10^{6}$ cells i.p. into $\mathrm{BALB} / \mathrm{c}$ mice previously primed with pristane (Aldrich Chemical Co., Milwaukee, Wis.). Antibody-containing ascites fluid was used in all subsequent experiments. Ig class of each antibody was determined by Ouchterlony immunodiffusion in $1 \%$ agar with specific goat anti-mouse immunoglobulin reagents (Litton Bionetics, Div. Litton Industries, Inc., Kensington, Md.). With the aid of appropriate target cells the antibodies were determined to be lytic by the chromium release assay (21).

Isolation of human cell fractions. Human granulocytes were prepared from the peripheral blood of healthy volunteer donors by Ficoll-Hypaque density gradient centrifugation (22). The pellet was diluted 1:1 with Hanks' balanced salt solution containing $0.4 \%$ high molecular weight dextran (Dextran T500, Pharmacia Fine Chemicals, Div. of Pharmacia Inc., Piscataway, N. J.), and contaminating erythrocytes were removed by unit gravity sedimentation. After washing, the granulocyte pellet was treated with $0.17 \mathrm{M} \mathrm{NH}_{4} \mathrm{Cl}$ to remove any remaining erythrocytes by hypotonic lysis. Granulocyte preparations were $>98 \%$ pure by morphological criteria.

Peripheral blood mononuclear cells were isolated from the interface of Ficoll-Hypaque-separated peripheral blood. Monocyte-enriched adherent cells were obtained by incubating peripheral blood mononuclear cells from defibrinated blood on plastic culture dishes (Falcon Labware, Div. of Becton-Dickinson \& Co., Oxnard, Calif.) in the presence of $10 \%$ pooled human $\mathrm{AB}$ serum for $60 \mathrm{~min}$ at $37^{\circ} \mathrm{C}$. Adherent cells were routinely 60-80\% monocytes as defined by Wright-Giemsa staining and positive staining for alphanapthylacetate esterase (nonspecific esterase [23]). T lymphocytes were isolated by rosetting with $5 \%$ sheep erythrocytes (Microbiological Associates, Walkersville, Md.). Purity of these preparations was also determined by monoclonal antibodies specific for monocytes (anti-Mo2) and T cells (anti-T3) $(23,24)$. Platelets were prepared from heparinized blood by low-speed centrifugation to remove cells, and purity was assessed by microscopic examination. In all cases, reactivity is expressed as the percentage of a cell population more fluorescent than control cells in an indirect immunofluorescence assay. The control antibody was a murine monoclonal IgG or IgM previously shown to be nonreactive with test cells. Ascites diluted 1/100 to 1/500 was used in all cases.

Human bone marrow was obtained from healthy volunteers by aspiration into preservative-free heparin-containing syringes. Erythrocytes and mature neutrophils were removed by Ficoll-Hypaque sedimentation. In some experiments, plastic adherence was used to remove monocytes.

Human leukemia cells. Tumor cells were obtained from the peripheral blood or bone marrow of 72 patients with acute myeloblastic leukemia (AML), nine patients with chronic myelogenous leukemia (CML), six patients with blast crisis phase of CML, 30 patients with acute lymphocytic leukemia (ALL), and 14 patients with chronic lymphocytic leukemia. Expression of $B$ and $T$ cell antigens was determined by reactivity with monoclonal antibodies, anti-B 1 (25) and anti-T3 (24), respectively.

Ia antigen was determined by reactivity with anti-I2 (26). Identification of non-B, non-T cell ALL was ascertained by reactivity with monoclonal antibody anti-common acute 
lymphocytic leukemia antigen (CALLA) (J5) (27). All tumor cells were cryopreserved until use in the vapor phase of liquid nitrogen in $10 \%$ dimethylsulfoxide and $20 \%$ FCS. Some bone marrow samples were thawed in the presence of deoxyribonuclease I, $10 \mu \mathrm{g} / \mathrm{ml}$ (Millipore Corp., Freehold, N. J.) to prevent agglutination of myeloid cells. During analysis on the fluorescence-activated cell sorter (FACS), windows were selected with the aid of the light scatter profile to include the size population of the leukemic cells, as confirmed by microscopic examination.

The diagnosis and subgrouping of AML patients was determined by morphology of Wright-Giemsa stained cytocentrifuge preparations, and by standard histochemical stains, including peroxidase (28), napthol AS-D chloroacetate esterase (specific esterase [23]), and alpha-napthyl acetate esterase (nonspecific esterase [23]). By these procedures, AML patients were subclassified as acute promyelocytic leukemia (APL, four patients), acute myelomonocytic leukemia and acute monocytic leukemia (AMML and $A M O L$, respectively, 19 patients), and undifferentiated AML (49 patients) (29). For all patients' leukemia, the analyzed population of cells contained $>80 \%$ tumor cells, and generally $>90 \%$ tumor cells. A positive reaction was arbitrarily taken as $>20 \%$ of test cells staining more intensely in an indirect immunofluorescence assay than with control antibody (a nonreactive monoclonal Ig used at an equivalent concentration to test antibody).

Human cell lines. The myeloid leukemia cell line KG-1 was supplied by Dr. David Golde, University of CaliforniaLos Angeles School of Medicine, Los Angeles, Calif. HPBALL and 45 were the gift of Dr. J. Minowada, Rosewell Park Memorial Institute, Buffalo, N. Y. All other cell lines (Table IV) were provided by Dr. Herbert Lazarus, Sidney Farber Cancer Institute.

Fluorescence-activated cell sorter analysis. FACS was used to separate Ficoll-Hypaque-sedimented normal bone marrow cells into a fraction staining brightly with test antibody (MY8), as described above, and a fraction that did not react with test antibody, as compared with control. Cells were collected into $50 \%$ FCS and cytocentrifuge preparations made for staining with Wright-Giemsa and cytochemical stains. In some experiments, cells were collected sterilely, and assayed for granulocyte/macrophage colony-forming unit (CFU-GM) cells as described below.

CFU-GM assay. The CFU-GM was assayed by plating $1 \times 10^{5}$ normal bone marrow cells in Iscove's modified Dulbecco's medium, $20 \%$ FCS, $0.3 \%$ agar over a feeder layer of $1 \times 10^{6}$ peripheral blood leukocytes in $0.5 \%$ agar (3). After a 14-d incubation, the number of colonies with $>40$ cells were counted with an inverted microscope. In some experiments, the agar overlayers were separated from the underlayers, dried onto glass slides, and stained for peroxidase activity to detect myeloid colonies $(28,30)$.

Complement-mediated lysis of bone marrow cells with specific antibody. Reactivity with the CFU-GM cell was also assayed by complement-mediated lysis of normal bone marrow cells. $5 \times 10^{6}$ Ficoll-Hypaque bone marrow cells were incubated at $4^{\circ} \mathrm{C}$ in $1.0 \mathrm{ml}$ of media containing 1:100 dilution of hybridoma antibody for $1 \mathrm{~h}$. After washing, the cells were resuspended in rabbit serum (Pel-Freeze $\mathrm{Bi}$ ologicals, Inc., Rogers, Ark.) diluted 1/5 in RPMI 1640. After incubation for $1 \mathrm{~h}$ at $37^{\circ} \mathrm{C}$, the cells were washed and suspended in Iscove's modified Dulbecco's medium with $20 \%$ FCS and CFU-GM assay performed as described. Monoclonal anti-Ia was used as a positive control $(26,31)$.

Fc receptor analysis. The possibility that MY3, MY4, MY7, or MY8 bind to myeloid cells via Fc receptors was investigated by competitive binding studies. Granulocytes or monocytes were incubated with $20 \%$ human AB serum. An indirect immunofluorescence assay was then performed with test antibody to examine for loss of fluorescent staining, as compared with a similar assay done without the presence of human serum. Competitive inhibition of erythrocyte antiserum rosette formation was tested as previously described (21).

Differentiation of myeloid cell lines. Changes in myeloid surface antigens during chemically induced differentiation of certain myeloid cell lines were examined with indirect immunofluorescence as described above. Changes in myeloid surface antigens were determined in induced cells relative to uninduced control cells. The promyelocytic cell line HL60 (32) was induced with $1.1 \%$ dimethylsulfoxide (DMSO) (33), or $10 \%$ phytohemagglutinin-stimulated leukocyteconditioned medium (PHA-LCM) (34), prepared according to the method of Aye et al. (35). Cells were cultured in plastic tissue culture dishes (Falcon) at an initial cell concentration of $1.0 \times 10^{6}$ cells $/ \mathrm{ml}$. Aliquots were removed daily from cultures containing the inducing agent or control cultures for evaluation of changes in morphology, cytochemical stains, and FACS analysis. Adherent cells were removed where necessary by vigorous pipetting and scraping with a rubber policeman. Similar experiments were performed with the myeloid cell line KG-1 (36), which was cultured in the presence of $10 \mathrm{nM}$ 12-O-tetradecanoylphorbol-13acetate (TPA, Sigma Chemical Co., St. Louis, Mo.) (37), and also with the histiocytic lymphoma cell line U937 (38), which was grown in 10\% PHA-LCM as inducing agent (39).

In experiments using PHA-LCM as an inducing agent, control cells were cultured in the presence of an equivalent amount of phytohemagglutinin $\left(4 \times 10^{-7} \mathrm{~g} / \mathrm{ml}\right)$. In experiments using TPA as an inducing agent, control cells were cultured in the presence of an equivalent amount of diluent for TPA $(0.01 \%$ acetone $)$.

\section{RESULTS}

Development and initial characterization of monoclonal antibodies directed against AML cells. A BALB/c mouse was immunized with the blasts from a patient with AMML, and its splenocytes fused with NS1 myeloma cells to form hybridomas. This resulted in 331 primary clones, which were screened for the presence of antibody reactive with the original leukemic cells. 80 wells contained reactive antibody, and of these 12 were found that did not react with the autologous B lymphoblastoid cell line, Laz 334 . These 12 were recloned by limiting dilution, and passaged in the peritoneal cavity of $\mathrm{BALB} / \mathrm{c}$ mice to produce ascites with high-titer monoclonal antibody. Four of these hybridoma clones have undergone further characterization and form the basis of this report. Anti-MY3 is an IgM, anti-MY4 is an IgG $_{2 a}$, anti-MY7 is an $\mathrm{IgG}_{1}$, and anti-MY8 is an $\mathrm{IgG}_{\mathbf{2 b}}$.

Expression of MY3, MY4, MY7, and MY8 on normal peripheral blood cells. Table I indicates the expression of the antigens defined by anti-MY3, MY4, MY7, and MY8 on normal peripheral blood and bone marrow cells. As can be seen, the expression of MY3, MY4, MY7, and MY8 is limited to myeloid cells. Peripheral blood and bone marrow monocytes (adherent cells) were strongly fluorescent with anti-MY3 and MY4, 
TABLE I

Reactivity with Normal Peripheral Blood and Bone Marrow Cells

\begin{tabular}{lcccc}
\hline & \multicolumn{4}{c}{ Positive cells* } \\
\cline { 2 - 5 } \multicolumn{1}{c}{ Cellular fraction } & MY3 & MY4 & MY7 & MY8 \\
\hline & & & $\%$ \\
Peripheral blood & & & \\
Unfractionated & $7 \pm 2$ & $9 \pm 2$ & $4 \pm 3$ & $8 \pm 3$ \\
Adherent cells $\$$ & $81 \pm 6$ & $85 \pm 4$ & $21 \pm 3$ & $77 \pm 8$ \\
Nonadherent (monocyte-depleted) & $2 \pm 1$ & $3 \pm 2$ & $3 \pm 1$ & $2 \pm 1$ \\
E-rosette positive (T cells)" & $1 \pm 1$ & $1 \pm 1$ & $2 \pm 2$ & $2 \pm 1$ \\
Granulocytes & $8 \pm 3$ & $28 \pm 3$ & $72 \pm 8$ & $71 \pm 9$ \\
Erythrocytes & 0 & 0 & 0 & 0 \\
Platelets & 0 & 0 & 0 & 0 \\
Bone marrow & & & & \\
Unfractionated $\ddagger$ & $4 \pm 2$ & $5 \pm 2$ & $5 \pm 2$ & $32 \pm 4$ \\
Adherent cells & $32 \pm 8$ & $42 \pm 7$ & $22 \pm 12$ & $46 \pm 12$ \\
Nonadherent cells (monocyte-depleted) & $3 \pm 3$ & $2 \pm 3$ & $5 \pm 3$ & $32 \pm 8$ \\
\hline
\end{tabular}

* Expressed as the mean $\pm \mathrm{SD}$ of cells fluorescent above background in an indirect immunofluorescence assay.

\$ Ficoll-Hypaque separated.

$\$ 75 \%$ nonspecific esterase positive.

"At least $85 \%$ reactive with anti-T3.

whereas granulocytes were very weakly fluorescent. In contrast, anti-MY7 staining resulted in intense fluorescence of granulocytes but slight fluorescence of monocytes. MY8 was detected equally on granulocytes and monocytes. Reactivity with monocytes was not the result of antibody binding to monocyte-bound platelets, as reactivity with monocytes prepared from defibrinated (platelet-poor) blood was equivalent to standard preparations (data not shown). Lymphocytes, erythrocytes, and platelets do not express detectable amounts of MY3, MY4, MY7, or MY8. These antigens were expressed uniformly by the monocytes of 12 randomly chosen individuals.

Since monocytes and granulocytes are rich in $\mathrm{Fc}$ receptors, blocking experiments were designed to test the possibility that these antibodies bind to $F_{c}$ receptors. Preincubation of monocytes with anti-MY3, MY4, MY7, and MY8 failed to inhibit rosette formation with 7S antibody (EA)-coated sheep erythrocytes relative to control ascites. Moreover, preincubation of monocytes or granulocytes with medium containing $20 \%$ human $\mathrm{AB}$ serum did not alter binding relative to preincubation in nonserum-containing medium.

Expression of MY3, MY4, MY7, and MY8 on normal bone marrow cells. In normal bone marrow, MY3, MY4, and MY7 were detected on only a small number of cells (Table I). In contrast, MY8 was expressed by $32 \%$ of bone marrow cells and further efforts to identify the MY8 antigen-positive bone marrow cells were undertaken. Bone marrow cells were separated by fluorescence-activated cell sorting after staining with anti-MY8 and fluorescein-conjugated goat antimouse immunoglobulin (Fig. 1). Cytocentrifuge slide preparations of the positive and negative fractions were stained with Wright-Giemsa and assayed for peroxidase. As shown in Table II, the MY8-positive fraction consisted of granulocyte precursor cells including promyelocytes. There were insufficient numbers of identifiable myeloblasts, eosinophils, or basophils to determine reactivity with those cells. Erythroid precursors and lymphocytes did not express the MY8 antigen. The cells of the positive fraction were $99 \%$ peroxidase positive, while the negative fraction contained $<10 \%$ peroxidase-positive cells.

Lack of expression of MY3, MY4, and MY8 on myeloid precursor cells. Normal bone marrow cells were incubated with anti-MY3, MY4, MY8, Ia, or no antibody, followed by addition of complement. Anti-MY7 is not a lytic antibody and was not included in these experiments. The number of remaining viable CFUGM cells was not decreased by pretreatment with antiMY3, MY4, or MY8, as compared with pretreatment with complement alone in each of the three experiments. In contrast, anti-Ia abolished $\geq 75 \%$ of myeloid colony growth in all experiments (data not shown). In one experiment, colonies were stained for nonspecific esterase (30) to identify monocyte containing colonies. The percentage of colonies showing some or all cells NSE positive was not significantly different after pretreatment with anti-MY3, MY4, or MY8, as compared 


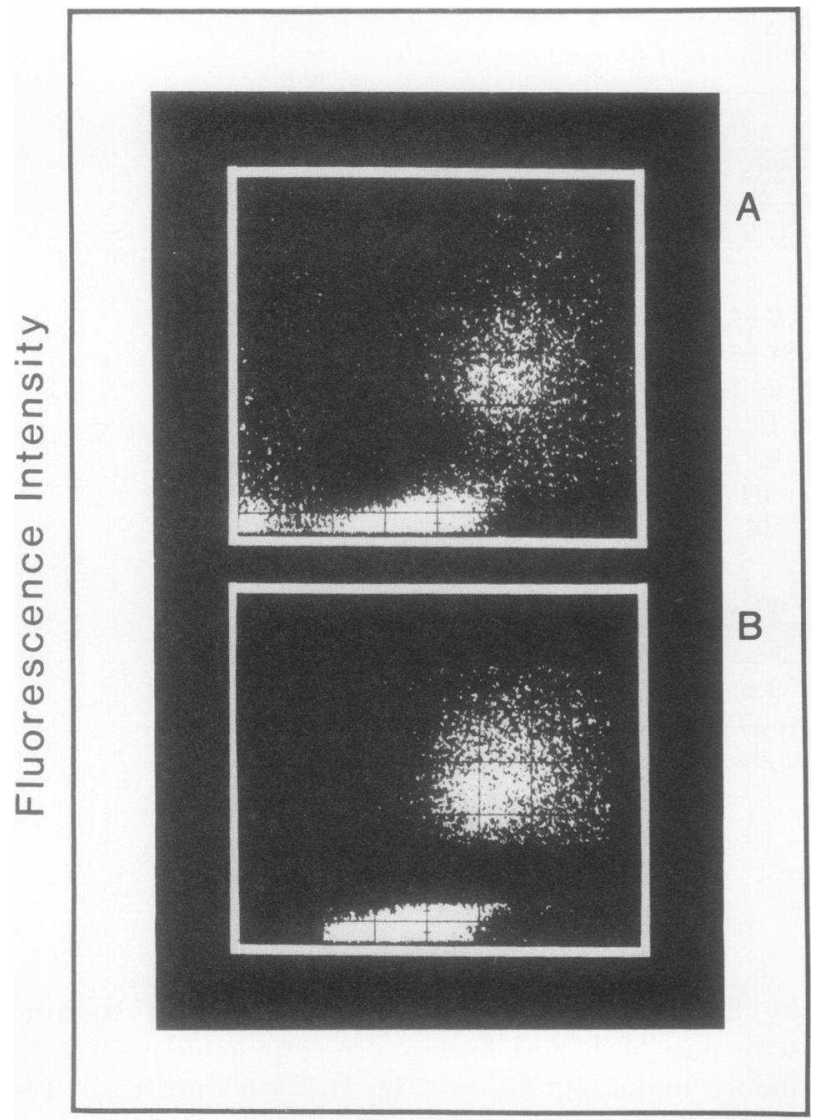

Cell Size

FIgURE 1 (A) Reactivity of normal bone marrow cells with anti-MY8 antiserum. FACS profile of normal bone marrow cells reacted by indirect immunofluorescence with anti-MY8. Vertical axis: relative fluorescence intensity; horizontal axis: increasing relative cell size. (B) FACS profile illustrating preselected windows chosen for sorting MY8 antigen-positive normal bone marrow cells (bright fluorescence intensity) from MY8 antigen-negative cells (dim fluorescence intensity). Erythrocytes were excluded by size. A 488-nm argon ion laser line set to $600-\mathrm{mW}$ output power was used with photomultiplier tube voltage set to $650 \mathrm{~V}$. Each dot represents a single cell.

with no antibody treatment $(\sim 60 \%)$. It thus appears that MY3, MY4, and MY8 are not expressed on the CFU-GM cell.

The lack of expression of MY8 on the CFU-GM cell was confirmed by assaying the FACS-separated MY8 antigen positive and negative populations (Fig. 1) of normal bone marrow for the presence of CFU-GM cells. The CFU-GM cells were found entirely in the MY8-negative fraction (Table II).

Expression of MY3, MY4, MY7, and MY8 by malignant myeloid and lymphoid cells. Table III indicates the expression of MY3, MY4, MY7, and MY8 on malignant cells from patients with various leukemias. It can be seen that none of these antigens is expressed on lymphocytic leukemias of either T or B cells. MY3 and MY4, which are detected on normal monocytes, are expressed by 33 and $35 \%$, respectively, of all AML patients tested, with a strong tendency towards greater antibody binding by leukemic cells with monocytic characteristics ( $>90 \%$ of AMoL, AMML). Anti-MY3 and MY4 have a similar, but not identical pattern of reactivity with $A M L$ patients, and may identify similar, but apparently not identical, antigens. MY7 was detected on the majority of AML myeloblasts, and was equally expressed by leukemic cells that were NSE positive (AMoL, AMML) as those that were NSE negative. Overall, $79 \%$ of AML patients' cells expressed MY7. Four patients with APL were tested, and MY7 was detected on two. Six patients with the blast crisis phase of CML were studied. The cells of four patients with "myeloid" blast crisis (characterized by morphology, peroxidase reaction, and lack of lymphocyte surface markers [40]) reacted with antiMY7, and three patients bore MY8. MY7 and MY8 were not detected on "lymphoid" blast crisis cells (characterized by morphology and presence of lymphocyte surface markers, including CALLA [27]). MY3 and MY4 were not present on myeloid or lymphoid blast crisis cells.

Expression of MY3, MY4, MY7, and MY8 on cultured human cell lines. Table IV indicates the expression of MY3, MY4, MY7, and MY8 on 18 different cultured human cell lines. As shown, there is no

TABLE II

Comparison of MY8 Antigen Positive and Negative Normal Bone Marrow Cells Separated by FACS

\begin{tabular}{lrcr}
\hline \multicolumn{1}{c}{ Cell type } & Unsorted $^{*}$ & Positive & Negative \\
\hline & & $\%$ & \\
Erythroid precursors & 28 & 0.5 & 57 \\
Blasts & 1 & 0 & 3 \\
Promyelocytes & 5 & 10 & 2 \\
Myelocytes, metamyelocytes & 28 & 40 & 0 \\
Neutrophilic bands & 18 & 38 & 0 \\
Neutrophils & 3 & 6 & 1 \\
Eosinophils & 1 & 1 & 1 \\
Basophils & 1 & 2 & 0 \\
Monocytes & 3 & 2 & 2 \\
Lymphocytes & 12 & 0.5 & 33 \\
Plasma cells & 0 & 0 & 1 \\
Peroxidase-positive cells & 55 & 99 & 9 \\
CFU-GM/105 nucleated bone & & & \\
$\quad$ marrow cells $\$$ & 32 & 0 & 110 \\
\hline
\end{tabular}

* The data of one experiment is presented. Equivalent results were obtained in a second experiment with bone marrow from another donor.

$\ddagger$ Units per $10^{5}$ nucleated bone marrow cells. 
expression of these antigens on lymphoblastoid cell lines of T or B lineage. In contrast, several cell lines of myeloid derivation express these antigens. HL60, a promyelocytic cell line, shows weak fluorescence staining with anti-MY3 and MY4, and stronger expression of MY7 and MY8. KG-1, derived from an AML patient, expresses MY7; and K562, originally established from the pleural fluid of a patient in CML blast crisis (41), expresses MY7 antigen. U937, a histiocytic lymphoma cell line with several macrophagelike features expresses both MY7 and MY8.

Expression of MY3, MY4, MY7, and MY8 on cultured human cell lines during induced differentiation. Cells of several human myeloid cell lines can be induced to undergo differentiation into more mature myeloid cells by a variety of chemical-inducing agents. The human promyelocytic leukemia cell line HL60 can be induced to differentiate into macrophagelike cells by either leukocyte-conditioned media (34) or by phorbol diester (42). These differentiated cells develop morphological and cytochemical characteristics of macrophages, and acquire mature myeloid cell functions such as response to chemotactic factors and phagocytosis (43). DMSO has been shown to induce dif-

TABLE III

Reactivity with Myeloid and Lymphoid Leukemias

\begin{tabular}{|c|c|c|c|c|c|}
\hline \multirow[b]{2}{*}{ Leukemia } & \multirow{2}{*}{$\begin{array}{c}\text { No. of } \\
\text { patients } \\
\text { tested }\end{array}$} & \multicolumn{4}{|c|}{ No. Positive } \\
\hline & & MY3 & MY4 & MY7 & MY8 \\
\hline \multicolumn{6}{|l|}{ AML } \\
\hline APL & 4 & $0^{*}$ & 0 & 2 & 0 \\
\hline AML & 49 & 6 & 7 & 41 & 20 \\
\hline AMML, AMoL & 19 & 18 & 18 & 14 & 15 \\
\hline Total AML & 72 & 24 & 25 & 57 & 35 \\
\hline \multicolumn{6}{|l|}{ CML } \\
\hline Stable phase & 9 & 1 & 1 & 5 & 7 \\
\hline Blast crisis, myeloid & 4 & 0 & 0 & 4 & 3 \\
\hline \multicolumn{6}{|l|}{ Blast crisis, lymphoid } \\
\hline CALLA+ & 2 & 0 & 0 & 0 & 0 \\
\hline \multicolumn{6}{|l|}{ ALL } \\
\hline Non-T, non-B, CALLA ${ }^{+}$ & 11 & 0 & 0 & 0 & 0 \\
\hline Non-T, non-B, CALLA- & 8 & 0 & 0 & 0 & 0 \\
\hline $\mathrm{T}$ cell & 11 & 0 & 0 & 0 & 0 \\
\hline \multicolumn{6}{|l|}{$\begin{array}{l}\text { Chronic lymphocytic } \\
\text { leukemia }\end{array}$} \\
\hline B cell & 11 & 0 & 0 & 0 & 0 \\
\hline $\mathrm{T}$ cell & 3 & 0 & 0 & 0 & 0 \\
\hline
\end{tabular}

*A positive reaction was defined as a minimum of $20 \%$ of a leukemic cell population staining more intensely with test antibody than control antibody in an indirect immunofluorescence assay. Patients were selected with $>60 \%$ leukemic cells, and generally $>80 \%$. The number of patients expressing each antigen is indicated.
TABLE IV

Reactivity with Cultured Human Cell Lines

\begin{tabular}{|c|c|c|c|c|}
\hline \multirow[b]{2}{*}{ Cell line } & \multicolumn{4}{|c|}{ Antibody reactivity } \\
\hline & MY3 & MY4 & MY7 & MY8 \\
\hline \multicolumn{5}{|l|}{ AML } \\
\hline HL60 (promyelocytic) & $+1-*$ & $+1-$ & ++ & + \\
\hline KG-1 & - & - & ++ & - \\
\hline \multicolumn{5}{|l|}{ CML-blast crisis } \\
\hline K562 & - & - & $+1-$ & - \\
\hline NALM-1§ & - & - & - & - \\
\hline \multicolumn{5}{|l|}{ ALL cell lines ( $T$ cells) } \\
\hline CEM & - & - & - & - \\
\hline HPB-ALL & - & - & - & - \\
\hline 45 (KARPAS) & - & - & - & - \\
\hline Molt-4 & - & - & - & - \\
\hline HSB & - & - & - & - \\
\hline \multicolumn{5}{|l|}{ ALL cell lines $\left(\mathrm{CALLA}^{+}\right)$} \\
\hline Laz 221 & - & - & - & - \\
\hline \multicolumn{5}{|l|}{ B cell lines" } \\
\hline JY & - & - & - & - \\
\hline Laz 153 & - & - & - & - \\
\hline Laz 325 & - & - & - & - \\
\hline Laz 388 & - & - & - & - \\
\hline \multicolumn{5}{|l|}{ Burkitt's lymphoma } \\
\hline Daudi & - & - & - & - \\
\hline Ramos & - & - & - & - \\
\hline Raji & - & - & - & - \\
\hline \multicolumn{5}{|l|}{ Histiocytic lymphoma } \\
\hline U937 & - & $+1-$ & ++ & ++ \\
\hline
\end{tabular}

$*+$, reactive; - , non-reactive; $+/-$, weakly reactive; ++ , strongly reactive.

$\ddagger$ myeloid blast crisis.

$\$$ lymphoid blast crisis.

" Epstein-Barr virus transformed B cells.

ferentiation of HL60 cells into granulocyte-like cells (33). Morphological and functional evidence of inducible differentiation has also been described for the histiocytic lymphoma cell line U937, and the AML cell line KG-1, which develop macrophage characteristics after exposure to PHA-LCM (39) or TPA (37), respectively. It was thus of interest to determine whether the process of in vitro differentiation was associated with any changes in cell surface myeloid antigens.

Table V shows the expression of MY3, MY4, MY7, and MY8 on cell lines HL60, KG-1, and U937 before and after exposure to the appropriate inducing agent as indicated. In each case, aliquots were removed from cultures daily to assess morphological changes, cell count, viability, and cell surface antigens. For all cell lines, viability remained $>90 \%$ through the period of 
TABLE V

Changes in Cell Surface Antigens with Differentiation of Cultured Cell Lines

\begin{tabular}{llccccc}
\hline Cell line & \multicolumn{1}{c}{ Treatment } & $\begin{array}{c}\text { Length of } \\
\text { treatment }\end{array}$ & MY3 & MY4 & MY7 & MY8 \\
\hline \multirow{3}{*}{ HL60 } & Control & $d$ & & & $\%$ & \\
& DMSO (1.1\%) & 4 & $45 \pm 5$ & $49 \pm 5$ & $90 \pm 8$ & $58 \pm 6$ \\
& PHA-LCM (10\%) & 4 & $50 \pm 12$ & $54 \pm 8$ & $92 \pm 5$ & $51 \pm 11$ \\
U937 & Control & & 0 & $1 \pm 1$ & $94 \pm 3$ & $78 \pm 4$ \\
& PHA-LCM & 5 & $14 \pm 3$ & $23 \pm 2$ & $62 \pm 10$ & $82 \pm 2$ \\
KG-1 & Control & & 0 & 0 & $27 \pm 5$ & 0 \\
& TPA (10 $n M)$ & 4 & $2 \pm 1$ & $1 \pm 1$ & $83 \pm 2$ & $2 \pm 1$ \\
\hline
\end{tabular}

* Percentage of each cell population staining more intensely with test antibody than control antibody in an indirect immunofluorescence assay, expressed as the mean of three experiments \pm SD.

observation. As noted by others, exposure of these cell lines to inducing agent leads to a dose-dependent reduction in cell growth. Under the conditions described here, final concentrations of induced cells were $50-75 \%$ of control cell cultures in multiple experiments. Cells cultured in the presence of appropriate control media grew at a rate indistinguishable from untreated cells grown in standard media (data not shown).

Exposure of HL60 cells to DMSO or PHA-LCM as described in Table $\mathrm{V}$ induces the expression of MY3, MY4, and MY8 on a significant fraction of cultured cells, as compared with control cultured cells, as detected by an indirect immunofluorescence assay. MY7 antigen is expressed by both control and differentiated HL60 cells. Removing culture aliquots daily for FACS analysis demonstrated that increased expression of MY3 and MY4 could be detected as early as $24 \mathrm{~h}$ after induction, and increased linearly for $4 \mathrm{~d}$ to the maximum value, which is indicated in Table V. At this time, virtually all cells have undergone morphological change, and show decreased staining for myeloperoxidase ( $<25 \%$ of cells positive). PHALCM treated cells (but not DMSO-treated cells) show increased cytochemical demonstration of NSE (>90\% cells positive) and will adhere to plastic. These findings suggest that among the biochemical events occurring during the differentiation of HL60 promyelocytes is expression of antigens MY3, MY4, and MY8. It is noteworthy that although DMSO and PHA-LCM produce differentiated HL60 cells that are not alike, the induced alterations in myeloid antigens are similar.

In similar experiments, the cell line U937 was induced with PHA-LCM, and myeloid antigen expression was determined as described above. The monocyte antigens MY3 and MY4 became detectable on a subset (14 and $23 \%$, respectively) of the induced cell population, but remain negligible on control cultured cells. Coincident with increased expression of MY3 and MY4, induced U937 cells demonstrated increased adherence and increased staining intensity for NSE (39). Expression of MY7 decreased from 94 to $62 \%$.

Exposure of the cell line KG-1 to TPA increased the expression of MY7 from 27 to $>80 \%$, without change in MY3, MY4, or MY8. Morphological changes did occur, and adherence increased, although this was less marked with KG-1 than with HL60 in these experiments. Cell viability decreased with exposure to TPA for $>4 \mathrm{~d}$.

Antibody absorption studies. To demonstrate that these antisera were monoclonal, cross-absorption studies were performed. Diluted ascites was incubated with sufficient target cells to remove reactivity with these target cells, and then tested for residual antibody binding to other cell types. Absorption of anti-MY7 and MY8 with granulocytes resulted in complete loss of reactivity with U937, HL60, and AMML cells. Similarly, absorption of anti-MY3 and MY4 with monocytes resulted in loss of reactivity with AMML cells. It thus appears that the antigens detected on mature normal myeloid cells are shared by myeloid leukemia cells.

\section{DISCUSSION}

In this report, we describe the identification of four antigens (MY3, MY4, MY7, and MY8) expressed by subsets of both normal and malignant myeloid cells. These antigens are defined by monoclonal antibodies derived from a fusion between NS1 myeloma cells and splenocytes from a BALB/c mouse immunized with the blasts from a patient with AMML. MY3 and MY4 are expressed by peripheral blood and bone marrow monocytes. MY7 is expressed on normal granulocytes and by $\sim 5 \%$ of normal bone marrow cells. MY8 is expressed by both peripheral blood monocytes and granulocytes, and by all peroxidase-positive bone 
marrow granulocyte precursor cells (Tables I and II). None of these antigens as expressed by lymphocytes, erythrocytes, or platelets. It thus appears that of hematopoietic cells, these antigens are restricted to the myeloid system.

We have analyzed the myeloid surface antigen phenotypes of a variety of patients with myeloid leukemias with these specific antisera (Table III). Antigens associated with AML cells have been previously detected by a variety of heteroantisera (1115). Moreover, several monoclonal antibodies have been described that are reactive with myeloid cells and myeloid leukemia cells $(23,44,45)$. It is possible that analysis of specific surface antigens of myeloid leukemia cells may identify subgroups of AML patients with different prognosis or response to therapy.

The studies presented here with 72 AML patients demonstrate that the surface antigens of AML cells are heterogeneous. In correlating myeloid surface antigen phenotypes with the standard diagnostic procedures of morphology and cytochemical staining, we have demonstrated that expression of MY3 and MY4 identify the majority ( $>90 \%$ ) of AML patients subclassified as AMoL and AMML by morphology and nonspecific esterase content. Other subgroups of AML express MY3 and MY4 much less frequently. Only 12 and $14 \%$ of patients, respectively, with "undifferentiated" AML are positive, and APL patients were negative. The preferential expression of MY3 and MY4 on monocytic leukemia cells thus correlates with the strong expression of these antigens on normal peripheral blood and bone marrow monocytes.

MY7 antigen was detected on $82 \%$ of "undifferentiated" AML patients (41 of 49 ), and $79 \%$ of all AML patients studied. Anti-MY7 may be a valuable reagent for identification of myeloid leukemias, especially in those patients where standard diagnostic laboratory procedures are inconclusive. Lymphocytic malignancies have been uniformly negative. Of note, MY7 has been expressed by the leukemic cells of four patients with "myeloid" blast crisis of CML. Two patients with lymphoid (CALLA positive) blast crisis have been negative for MY7. Additionally, two of four patients with APL strongly expressed MY7, as did the promyelocytic cell line HL60.

MY8 antigen was expressed by about half of all AML patients, and was most likely to be expressed on NSE positive leukemias (79\%). It was somewhat more common on NSE negative AML than MY3 or MY4, in keeping with the expression of MY8 on granulocyte lineage cells as well as monocytes.

Some of the antigens described here may represent differentiation antigens of normal myeloid cells, in that they are lineage specific and appear at distinct stages of cellular maturation. MY3 and MY4 are expressed by peripheral blood monocytes, bone marrow monocytes, and by $<3 \%$ of remaining, nonadherent bone marrow cells. But the monocyte progenitor cells, the CFU-GM, do not express MY3 or MY4 by complement-dependent cytotoxicity testing, and thus MY3 and MY4 are acquired at a late stage of differentiation. MY8 is detected on all peroxidase-positive granulocyte precursors in the bone marrow, but the CFU-GM cell does not express MY8, as determined by cell sorting (Table II) and by complement lysis experiments. MY8 may represent a differentiation antigen shared by precursors of both monocytes and granulocytes more mature than the CFU-CM cell. Reactivity of anti-MY7 with the CFU-GM cells has not yet been determined. As most of the $72 \mathrm{AML}$ patients reported here expressed one or more of these myeloid surface differentiation antigens, it is evident that AML blasts express surface antigens that are more differentiated than those of the CFU-GM cells. Also, it is of interest that many AML cells express surface antigens characteristic of mature myeloid cells, despite morphologic and growth characteristics of very primitive cells. In some instances, myeloid leukemic cells may also be induced to undergo morphologic and functional differentiation (46-48). Thus, differentiation in leukemic cells may not be an "orderly" process, as appearance of certain mature membrane antigens may occur before development of morphological and functional maturity.

Further evidence that MY3, MY4, MY7, and MY8 may determine myeloid differentiation antigens comes from an examination of surface antigen changes in chemically induced differentiation of the myeloid leukemia cell lines HL60 and KG-1 and the histiocytic lymphoma cell line U937. When exposed to differentiating agents, HL60 cells have been shown to develop a number of immunologic, biochemical, and functional characteristics of mature myeloid cells, including complement receptors, phagocytosis, a 130,000-dalton membrane glycoprotein, chemotactic peptide receptors, and morphology consistent with maturing cells $(33,43,49)$. Exposure of HL60 cells to leukocyte-conditioned media or to TPA has been described to induce monocyte-like maturation, with development of NSE activity $(34,42)$. Similar experiments have shown that the cell lines KG-1 (37) and U937 (39) will develop morphologic and functional characteristics of monocytes when exposed to TPA or leukocyte-conditioned medium, respectively.

In the experiments presented here with HL60 and U937 cells, expression of the monocyte antigens MY3 and MY4 was linked to induction of differentiation, with maximum morphologic change $(\sim 5 \mathrm{~d}$ of culture). In experiments with HL60 cells, the intensity of expression of MY4 antigen was found to be directly correlated with both concentration of inducing agent (DMSO) and length of exposure (data not shown). MY8 antigen was also expressed more strongly on dif- 
ferentiated HL60 cells ( 12 to $58 \%$ ), but did not change on U937 or KG-1 cells. The cell line KG-1 did not acquire MY3, MY4, or MY8 antigens with prolonged exposure to TPA (10 $\mathrm{nM}$ maximum concentration). MY7 antigen increased from 27 to $80 \%$ with a 4 -d exposure to TPA. Thus, we have shown that induced differentiation in several myeloid cell lines results in the de novo expression or increased expression of several myeloid surface antigens that may also be differentiation antigens of normal myeloid cells. While differentiation of myeloid leukemic cell lines is easily studied, they may not be accurate models of normal cell differentiation. Further comparisons between leukemic cell lines and normal myeloid differentiation are necessary, and may be facilitated by the availability of the reagents such as described in this report.

\section{ACKNOWLEDGMENTS}

We would like to thank Mr. John Daley for technical expertise in cell sorting experiments, Mr. Herbert Levine for preparation of goat anti-mouse FITC reagents and for assistance in immunofluorescence assays, Dr. Herbert Lazarus for preparation of Epstein-Barr virus-transformed B cell lines, Ms. Susan McDonough for technical assistance, and Mrs. Nickie Clark and Ms. Karen Ellis Oshry for secretarial assistance.

This work was supported by National Institutes of Health grants CA-25369, CA-19589 Project 3, CA-09172, and CA28740 .

Dr. Griffin is supported in part by the Johanna C. Wood Foundation (Philadelphia, Pa.) and the Medical Foundation, (Boston, Mass.).

\section{REFERENCES}

1. Till, J. E., and E. A. McCulloch. 1961. A direct measurement of the radiation sensitivity of normal mouse bone marrow cells. Radiat. Res. 14: 213-222.

2. Bradley, T. R., and D. Metcalf. 1966. The growth of mouse bone marrow cells in vitro. Aust. J. Exp. Biol. Med. Sci. 44: $287-300$.

3. Pike, B. L., and W. A. Robinson. 1970. Human bone marrow colony growth in agar-gel.J. Cell. Physiol. 76: 77-84.

4. Golde, D. W., and M. J. Cline. 1972. Identification of the colony-stimulating cell in human peripheral blood. $J$. Clin. Invest. 51: 2981-2983.

5. Parker, J. W., and D. Metcalf. 1974. Production of colonystimulating factor in mitogen-stimulated lymphocyte cultures. J. Immunol. 112: 502-510.

6. Chess, L., and S. F. Schlossman. 1977. Human lymphocyte subpopulations. In Advances in Immunology. F. J. Dixon and H. G. Kunkel, editors. Academic Press, Inc., New York. 213-247.

7. Aisenberg, A. C., and K. J. Bloch. 1972. Immunoglobulins on the surface of neoplastic lymphocytes. N. Engl.J. Med. 287: 272-276.

8. Borella, L., and J. Sen. 1973. T cell surface markers on lymphoblasts from acute lymphocytic leukemia. J. Immunol. 111: 1257-1261.

9. Brouet, J. C., and M. Seligmann. 1978. The immunological classification of acute lymphoblastic leukemias. Cancer (Phila.). 42: 817-827.

10. Bloomfield, C. D., J. H. Kersey, R. D. Brunning, and K. J.
Gajl-Peczalska. 1976. Prognostic significance of lymphocyte surface markers in adult non-Hodgkins malignant lymphoma. Lancet. II: 1330-1333.

11. Metzgar, R. S., T. Mohanakumar, and D. S. Miller. 1972. Antigens specific for human lymphocytic and myeloid leukemic cells: detection by non-human primate antiserums. Science (Wash. D. C.). 178: 986-988.

12. Baker, M. A., R. E. Falk, J. Falk, and M. F. Greaves. 1976. Detection of monocyte specific antigen on human acute leukemia cells. Br. J. Haematol. 32: 13-19.

13. Roberts, M. M., and M. F. Greaves. 1978. Maturation linked expression of a myeloid cell surface antigen. $B r . J$. Haematol. 38: 439-452.

14. Mohanakumar, T., M. A. Baker, D. A. K. Roncari, and R. N. Taub. 1980. Serologic characterization of a monkey antiserum to human leukemic myeloblasts. Blood. 56: 934-936.

15. Billing, R., B. Clark, P. Koeffler, K. A. Foon, and P. I. Terasaki. 1980. Acute myelogenous leukemia heteroantisera. Clin. Immunol. Immunopathol. 16: 202-210.

16. Reinherz, E. L., P. C. Kung, G. Goldstein, R. H. Levey, and S. F. Schlossman. 1980. Discrete stages of human intrathymic differentiation: analysis of normal thymocytes and leukemic lymphoblasts of T-cell lineage. Proc. Natl. Acad. Sci. U. S. A. 77: 1588-1592.

17. Kohler, G., and C. Milstein. 1975. Continuous cultures of fused cells secreting antibody of pre-defined specificity. Nature (Lond.). 256: 495-497.

18. Kennett, R. H., K. A. Denis, A. S. Tung, and N. R. Klinman. 1978. Hybrid plasmacytoma production: fusion with adult spleen cells, monoclonal spleen fragments, neonatal spleen cells, and human spleen cells. Curr. Top. Microbiol. Immunol. 81: 77-91.

19. Margulies, D. H., W. M. Kuel, and M. D. Schraff. 1976. Somatic cell hybridization of mouse myeloma cells. Cell. 8: 405.

20. Levey, R. H., J. Dilley, and L. A. Lompson. 1979. Human leukemia cell surface antigens: mouse monoclonal antibodies as probes. Curr. Top. Microbiol. Immunol. 81: 164.

21. Todd, R. F., L. M. Nadler, and S. F. Schlossman. 1981. Antigens on human monocytes identified by monoclonal antibodies. J. Immunol. 126: 1435.

22. Boyum, A. 1968. Isolation of mononuclear cells and granulocytes from human blood. Scand. J. Clin. Lab. Invest. 21(Suppl. 97): 77-89.

23. Yam, L. T., C. Y. Li, and W. H. Crosby. 1971. Cytochemical identification of monocytes and granulocytes. Am. J. Clin. Pathol. 55: 283-290.

24. Reinherz, E. L., and S. F. Schlossman. 1980. The differentiation and function of human T lymphocytes: a review. Cell. 19: 821-827.

25. Stashenko, P., L. M. Nadler, R. Hardy, and S. F. Schlossman. 1980. Characterization of a human B lymphocyte specific antigen. J. Immunol. 125: 1678-1685.

26. Nadler, L. M., P. Stashenko, R. Hardy, J. M. Pesando, E. J. Yunis, and S. F. Schlossman. 1980. Monoclonal antibodies defining serologically distinct HLA-D/DR related Ia-like antigens in man. Human Immunol. 1: $77-90$.

27. Ritz, J., J. M. Pesando, J. Notis-McConarty, H. Lazarus, and S. F. Schlossman. 1980. A monoclonal antibody to human acute lymphoblastic leukemia antigen. Nature (Lond.). 283: 583-585.

28. Kaplow, L. S. 1965. Simplified myeloperoxidase stain using benzidine dihydrochloride. Blood. 26: 215-219.

29. Gralnick, H. R., D. A. G. Galton, D. Catovsky, C. Sultan, 
and J. M. Bennett. 1977. Classification of acute leukemia. Ann. Intern. Med. 87: 740-753.

30. Kubota, J., H. Mizoguchi, Y. Miura, T. Suda, and F. Takaku. 1980. A new technique for the cytochemical examination of human hematopoetic cells grown in agar gel. Exp. Hematol. (Copenh.). 8: 339-344.

31. Winchester, R. J., G. D. Ross, C. I. Jarowski, C. Y. Wang, J. Halper, and H. E. Broxmeyer. 1977. Expression of Ialike antigen molecules on human granulocytes during early phases of differentiation. Proc. Natl. Acad. Sci. U. S. A. 74: 4012-4016.

32. Collins, S. J., R. C. Gallo, and R. E. Gallagher. 1977. Continuous growth and differentiation of human myeloid leukemic cells in suspension culture. Nature (Lond.). 270: 347-349.

33. Collins, S. J., F. W. Ruscetti, R. E. Gallagher, and R. C. Gallo. 1978. Terminal differentiation of human promyelocytic leukemia cells induced by dimethyl sulfoxide and other polar compounds. Proc. Natl. Acad. Sci. U. S. A. 72: 2458-2462.

34. Elias, L., F. J. Wogenrich, J. M. Wallace, and J. Longmire. 1980. Altered pattern of differentiation and proliferation of HL-60 promyelocytic leukemia cells in the presence of leukocyte conditioned medium. Leuk. Res. 4: 301-307.

35. Aye, M. T., Y. Niho, J. E. Till, and E. A. McCulloch. 1974. Studies of leukemic cell populations in culture. Blood. 44: 205-210.

36. Koeffler, H. P., and D. W. Golde. 1978. Acute myelogenous leukemia: a human cell line responsive to colonystimulating activity. Science (Wash. D. C.). 200: 11531154.

37. Koeffler, H. P., and D. W. Golde. 1980. Human myeloid leukemia cell lines: a review. Blood. 56: 344-350.

38. Sundstrom, C., and K. Nilsson. 1976. Establishment and characterization of a human histiocytic lymphoma cell line (U937). Int. J. Cancer. 17: 565-577.

39. Koren, H. S., S. J. Anderson, and J. W. Larrick. 1979. In vitro activation of a human macrophage-like cell line. Nature (Lond.). 279: 328-330.

40. Rosenthal, S., G. P. Canellos, J. Whang-Peng, and H. R.
Gralnick. 1977. Blast crisis of chronic granulocytic leukemia: morphologic variants and therapeutic implications. Am. J. Med. 63: 542-547.

41. Lozzio, C. B., and B. B. Lozzio. 1975. Human chronic myelogenous leukemia cell line with positive Philadelphia chromosome. Blood. 45: 321-334.

42. Rovera, G., D. Santoli, and C. Damsky. 1979. Human promyelocytic leukemia cells in culture differentiate into macrophage-like cells when treated with a phorbol diester. Proc. Natl. Acad. Sci. U. S. A. 76: 2779-2783.

43. Gallagher, R., S. Collins, J. Trujillo, K. McCredie, M. Ahearn, S. Tsai, R. Metzgar, G. Aulakh, R. Ting, F. Ruscetti, and R. Gallo. 1979. Characterization of the continuous differentiating myeloid cell line (HL-60) from a patient with acute promyelocytic leukemia. Blood. 54: 713-733.

44. Breard, J., E. L. Reinherz, P. C. Kung, G. Goldstein, and S. F. Schlossman. 1980. A monoclonal antibody reactive with human peripheral blood monocytes. J. Immunol. 124: $1943-1948$.

45. Civin, C. I., J. Mirro, and M. L. Banquerigo. 1981. MY1, a new myeloid specific antigen identified by a mouse monoclonal antibody. Blood. 57: 842-845.

46. Sachs, L. 1978. Control of normal cell differentiation and the phenotypic reversion of malignancy in myeloid leukemia. Nature (Lond.). 274: 535-539.

47. Balkwell, F. R., and R. T. Oliver. 1974. Characterization of acute myeloid leukemia on the basis of differentiation in short term liquid culture. In Proceedings of the International Symposium on Human Lymphocyte Differentiation: Its Application to Cancer. B. Serrou and C. Rosenfeld, editors. North-Holland Publishing Co., Amsterdam. 373-376.

48. Koeffler, H. P., M. Bar-Eli, and M. Territo. 1980. Phorbol diester-influenced macrophage differentiation of leukemic blasts from patients with human myelogenous leukemia. J. Clin. Invest. 66: 1101-1108.

49. Gahmberg, C. G., K. Nilsson, and L. C. Andersson. 1979. Specific changes in the surface glycoprotein pattern of human promyelocytic leukemia cell line HL-60 during morphologic and functional differentiation. Proc. Natl. Acad. Sci. U. S. A. 76: 4087-4091. 